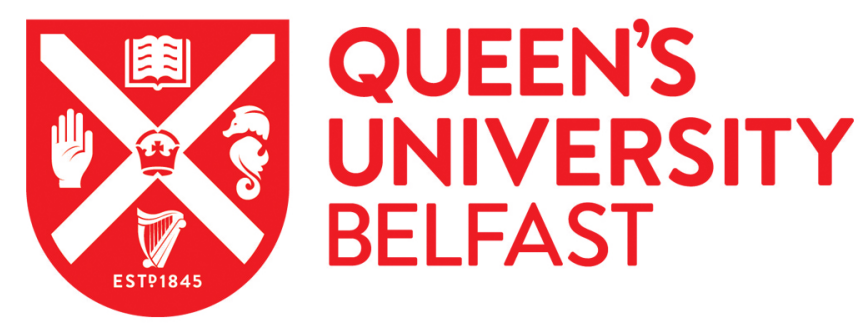

\title{
Adjustment strategies amongst black African and black Caribbean men following treatment for prostate cancer: findings from the Life After Prostate Cancer Diagnosis (LAPCD) study
}

Wagland, R., Nayoan, J., Matheson, L., Rivas, C., Brett, J., Collaço, N., Alexis, O., Gavin, A., Glaser, A. W., \& Watson, E. (2020). Adjustment strategies amongst black African and black Caribbean men following treatment for prostate cancer: findings from the Life After Prostate Cancer Diagnosis (LAPCD) study. European Journal of Cancer Care, 29(1), [e13183].

Published in:

European Journal of Cancer Care

Document Version:

Peer reviewed version

Queen's University Belfast - Research Portal:

Link to publication record in Queen's University Belfast Research Portal

Publisher rights

Copyright 2019 Wiley. This work is made available online in accordance with the publisher's policies. Please refer to any applicable terms of use of the publisher.

\section{General rights}

Copyright for the publications made accessible via the Queen's University Belfast Research Portal is retained by the author(s) and / or other copyright owners and it is a condition of accessing these publications that users recognise and abide by the legal requirements associated with these rights.

Take down policy

The Research Portal is Queen's institutional repository that provides access to Queen's research output. Every effort has been made to ensure that content in the Research Portal does not infringe any person's rights, or applicable UK laws. If you discover content in the

Research Portal that you believe breaches copyright or violates any law, please contact openaccess@qub.ac.uk. 


\title{
Adjustment strategies amongst black African and black Caribbean men following treatment for prostate cancer: findings from the Life After Prostate Cancer Diagnosis (LAPCD) study
}

Richard Wagland ${ }^{\mathrm{a}}$, Johana Nayoan ${ }^{\mathrm{b}}$, Lauren Matheson ${ }^{c}$, Carol Rivas ${ }^{\mathrm{d}} \mathrm{Jo} \mathrm{Brett}^{\mathrm{c}}$, Nicole Collaco ${ }^{c}$, Obrey Alexisc, Anna Gavin ${ }^{\mathrm{e}}$, Adam W Glaser ${ }^{f}$, Eila Watson ${ }^{c}$

\author{
${ }^{a}$ Health Sciences, University of Southampton, Southampton, UK \\ ${ }^{\mathrm{b}}$ Health Psychology Research Group, University College London, UK \\ ${ }^{\mathrm{C}}$ Faculty of Health and Life Sciences, Oxford Brookes University, Oxford, UK \\ ${ }^{\mathrm{d}}$ Social Science Research Unit, University College London, London, UK \\ e Northern Ireland Cancer Registry, Centre for Public Health, Queen's University Belfast \\ ${ }^{\mathrm{f}}$ Leeds Institute of Data Analytics, University of Leeds, Leeds, UK
}

\section{Corresponding author}

Dr Richard Wagland (ORCID No.: orcid.org/0000-0003-1825-7587)

Senior Research Fellow/ Lecturer

Health Sciences

University of Southampton

SO17 1BJ

Tel: 02380597868

Email: $\underline{\text { R.wagland@soton.ac.uk }}$

\section{Acknowledgements}

The Life After Prostate Cancer Diagnosis study was funded by the Movember Foundation, in partnership with Prostate Cancer UK, as part of the Prostate Cancer Outcomes programme, grant number BO26/MO. The authors thank all the men who responded to the survey. We acknowledge the following people for their contribution to the development, setting up and running of the study: Rebecca Mottram, Majorie Allen, Heather Kinnear, Conan Donnelly, Oonagh McSorley, Victoria Cairnduff, Linda Roberts, Adrian Slater, Picker Institute Europe, the LAPCD User Advisory Group and Clinical and Scientific Advisory Group. This study is based in part on information collected and quality assured by the National Cancer Registration and Analysis Service (part of Public Health England), the Northern Ireland Cancer Registry, the Welsh Cancer Intelligence \& Surveillance Unit and the Scottish Cancer Registry (part of the Public Health \& Intelligence Unit of NHS National Services Scotland).The work of cancer registries uses data provided by patents and collected by health services as part of their care and support. 


\section{Abstract}

Objective: To explore adjustment strategies adopted by Black African (BA) and Black Caribbean (BC) men in the UK as a response to the impact of PCa diagnosis and treatment effects.

Methods: Men were recruited through the UK-wide 'Life After Prostate Cancer Diagnosis' (LAPCD) survey. Telephone interviews were conducted with men $(n=14)$ with BA and BC backgrounds between 18-42 months post-diagnosis. Data were analysed using a Framework approach.

Results: Most men ( $n=12)$ were born outside the UK, were married $(n=9)$ and employed $(n=9)$. Median age was 66 years (range: $55-85$ ). Six overarching themes emerged: a strong reliance upon faith beliefs; maintaining a 'positive' front; work as distraction; non-disclosure of diagnosis even amongst family members, influenced by stigma and masculinity concerns; active awareness-raising amongst a minority, and; support-seeking from close community. A few men emphasised a need to 'pitch' awareness-raising messages appropriately. Potential links existed between faith beliefs, presenting a positive front, community support-seeking and local awareness-raising.

Conclusion: The provision of patient-centred care requires cultural sensitivity. Interventions that challenge stigma and mens' reluctance to disclose problems associated with PCa and treatment may encourage help-seeking for symptom support. Research is needed to determine how best awareness-raising messages should be conveyed to black men.

Keywords: Black African; Black Caribbean; Prostate cancer; survivorship; psychosocial

\section{INTRODUCTION}


An estimated 1.3 million men worldwide were diagnosed with PCa in 2012 (Bray et al. 2018). Prostate cancer ( $\mathrm{PCa}$ ) is the most commonly diagnosed cancer in men in the UK with over 47,000 diagnosed every year, and over 330,000 UK men estimated to be living with and beyond PCa diagnosis (CRUK 2018). Incidence of PCa within the UK is higher amongst men with black African (BA) and black Caribbean (BC) backgrounds compared to other ethnic groups (Rebbeck et al. 2013; Jones et al. 2014), with 1 in 4 developing the condition compared with 1 in 8 white men. Higher prevalence may be related to genetic factors (Haiman et al. 2011; Han et al. 2015). Black men are also more often diagnosed with later stage PCa than other groups, and experience poorer outcomes, as a consequence of delayed presentation of symptoms to health professionals (Ben-Shlomo et al. 2008; Chinegwundoh et al. 2006; Metcalf et al. 2008).

Improved treatment has led to increased overall survival rates from PCa (Bray et al. 2018), but many men experience post-treatment side effects such as incontinence, erectile dysfunction (ED), hot flushes, sweating and fatigue (Gavin et al. 2015). Recent systematic reviews have explored coping and adjustment of all men with PCa (Spenlow et al. 2018), and identified their supportive care needs (Paterson et al. 2015). A qualitative synthesis of research papers conducted by our team identified several issues that influence the experiences of black, Asian and minority ethnic (BAME) men compared to white majorities (Rivas et al. 2016). Other reviews have explored experiences specifically of black African (BA) and black Caribbean (BC) men (Bamidele et al. 2018a), and their perceptions of PCa (Pedersen et al. 2012). However, most studies included within these reviews were conducted in the US; only three explored post-treatment experiences of black men in the UK, predominantly of BC men, with only four BA participants included across those three studies (Rivas et al. 2016; Bamidele et al. 2018a). This study, part of a UK-wide, patient-reported outcome study, 'Life After Prostate Cancer Diagnosis' (LAPCD) (Downing et al. 2016), explored the approaches to adjustment to a $\mathrm{PCa}$ diagnosis amongst $\mathrm{BA}$ and $\mathrm{BC}$ men.

\section{METHODS}

LAPCD is a UK-wide population based mixed-methods study (Downing et al. 2016). In brief, all men 18-42 months post-diagnosis of PCa were identified through cancer registries in England, Wales and Northern Ireland and through hospital activity data in Scotland, and invited by their treating centre to complete a postal questionnaire. The LAPCD survey was conducted in England between December 2015-March 2016, and in Scotland, Northern Ireland and Wales between July-October 2016.

Respondents indicated willingness to be interviewed on the questionnaire, and were invited to interview.

A purposive sampling framework was used to recruit a wider sample of men to be interviewed ( $n=146$ ) by the survey provider (Picker Institute Europe), stratified by treatment type, but which included a range of men who indicated experience of one or more physical (e.g. urinary incontinence) and emotional problems (e.g. anxiety/depression). We specifically sought to include men from $\mathrm{BA}$ and $\mathrm{BC}$ backgrounds, and were sent contacts for all black men who indicated willingness to be interviewed $(n=24)$.

Cross-sectional, semi-structured telephone interviews were mainly conducted by one male researcher (RW), and by three female researchers (JN, LM, CR), between January-November 2016. A literature review (Rivas et al. 2016) was conducted to identify knowledge gaps and inform the topic guide, which was then reviewed and revised by clinical colleagues and members of the LAPCD user advisory group (UAG), with slight alterations made (Supplementary File 1). 
Amongst issues discussed, men were asked to describe the impact of PCa on their lives and families, their experiences of health professionals and services, and their coping strategies. Because participants were recruited across a wide geographical area in the UK, telephone interviews rather than face-to-face interviews were used to collect data. Interviews and verbal consent were digitally audio-recorded as separate files and uploaded to a secure environment. Themes reported in this paper were present for between a third $(n=4)$ and almost all $(n=12)$ participant transcripts. Thus, we believe we reached 'sampling adequacy' for theme construction (Bowen 2008).

\section{Analysis}

The study was not informed a priori by a theoretical model. We were interested in what emerged from the data itself, given the current lack of data in the UK context. Interviews were transcribed verbatim and managed using Nvivo v11.2 (QSR 2012), and analysed using Framework-Analysis; a matrix-based approach conducted through a series of stages (Ritchie \& Lewis 2011; Gale et al. 2013). The first stage involved familiarization, whereby researchers became immersed in the data and aware of key ideas and recurrent themes. Following each interview, researchers' summarised key issues, discussed and shared these amongst the research team for discussion.

A thematic coding framework of emerging themes was then developed. An initial draft of the coding framework was tested against five interview transcripts. Four researchers (JN,CR,EW, RW) independently coded the same transcripts, with codes then discussed. Double coding in Nvivo11 was conducted by three authors (CR, EW and RW) on $10 \%$ of interviews, giving proportion of agreement corrected for chance, with final Kappa scores of $\geqslant 80 \%$ (range 0.1346 (81.5\%) - 0.822 (96.7\%)) across all themes for all researchers. Three members of the UAG, one Black man (GC) and two white (JK, $\mathrm{HB})$, with a diagnosis of prostate cancer, were sent anonymised transcripts and the coding framework to check that identified themes adequately covered issues raised during interviews. GC provided reflections on his own experience that coincided with most themes. The complete dataset was then indexed, identifying data that corresponded to particular themes. Indexed data was then arranged in charts/matrices of themes, and key ideas and themes summarized in the charts/matrices with relationships between them identified. Extracts are provided to illustrate themes in the Findings section.

\section{Ethics}

Ethical and regulatory approvals and full consent were obtained from Newcastle and North Tyneside 1 Research Ethics Committee (15/NE/0036), Health Research Authority Confidentiality Advisory Group (15/CAG/0110), National Health Service (NHS) Scotland Public Benefit and Privacy Panel (0516-0364), and NHS Research and Development approval from Wales, Scotland, and Northern Ireland.

\section{FINDINGS}

The overall interview sample for the LAPCD study comprised 146 men. Although 24 BA and BC survey respondents were approached who indicated interest in being interviewed on returned surveys, only $58.3 \%$ (14/24) finally agreed to interview. This compares with $84.4 \%(146 / 173)$ amongst the overall LAPCD interview sample. Table 1 compares socio-demographic and clinical data between the overall sample and the $B A$ and $B C$ men. We interviewed ten $B A$ and four $B C$ men who had undergone a range of treatment modalities, including active surveillance (AS) $(n=1)$ and watchful waiting (WW) ( $n=1)$ (Table 2). The median age was 66 years, most men were born in Africa or the Caribbean $(n=12)$, rather than the UK $(n=2)$. Most participants were married $(n=9)$ and employed 
$(n=9)$, with a range of both professional and semi-skilled occupations. Duration of interviews ranged between 37-96 minutes (mean: 56 minutes; median: 51 minutes).

Six overarching and interrelated themes dominated that characterised the strategies employed to adapt to PCa.

\section{Reliance upon faith beliefs}

Almost all $B A$ and $B C$ participants $(n=12)$ described themselves as religious, with strong Christian faith beliefs and regular church attendance. Faith beliefs strongly influenced how most men viewed and adapted to their PCa diagnosis. Participants were used to seeking spiritual assistance to help cope with adversity: Africans are more religious. ... the more life is difficult, the more they seek spiritual help with their problems (Participant 14, BA). Most participants described drawing comfort and emotional strength from their faith, which helped them adjust to their PCa diagnosis: I' $m a$ person of faith. So faith is very, very significant, and helped me not go into depression (Participant 12, BA). One man also described his PCa diagnosis as an act of God (Participant 14, BA), of God testing his faith and character. Faith gave men meaning and a belief they were under God's protection:

I believe in whatever challenges that are thrown to you is thrown to you because God felt--he wanted to use it to see you in a position to handle it otherwise he wouldn't have thrown it at you. And I believe strongly that my faith will--- my faith that it's going to be cured. Strongly, I still hold onto that.' (Participant 14, BA)

All religious participants believed that, even with God's intervention, they should take responsibility for seeking medical help. Nevertheless, concerns were raised that some other men may leave responsibility for cure entirely to God, neglecting to seek professional help for symptoms of PCa or recurrence. Only two men (one BA and one $\mathrm{BC}$ ) described themselves as not holding spiritual beliefs, one calling himself an atheist, the other $a$ man of science.

\section{Maintaining a positive front}

Almost half the $\mathrm{BA}$ and $\mathrm{BC}$ participants described their response to their PCa diagnosis as accepting things as they happen, ...not to get stressed over things (Participant $8, \mathrm{BC}$ ). Moreover, several $\mathrm{BA}$ and $B C$ participants specifically described the importance to them of maintaining an outwardly 'positive' attitude, and to present an appearance that everything is well, even when this masked genuine concerns about their physical and social functioning. This attitude, described by two men as denying the negative (Participant 5, BA; Participant 3, BA), was reportedly part of some men's upbringing:

You don't confess the negative, so you're not taught to say: oh, I'm having a headache. Yeah? Say: Oh, it is well with me, rather than say: oh I have a splitting migraine, can you do something about that? ... They have to be positive always, ... without actually analysing what is happening and doing what is right. (Participant 5, BA)

Several men within the sample indicated they had not discussed issues such declining body image and worsening urine incontinence because they want everyone to think all is well with me (Participant 3, BA).

\section{The strategy of distraction}

Most participants $(n=10 / 14)$ at the time of the interview were in work and some carried on working after their retirement age (see table 2). This was a higher proportion than for the wider sample of interviewees. Most participants ascribed great important to their working lives: I put all my effort 
into my work (Participant 9, BA), while another described himself as a real workaholic (Participant 3, $B A)$. Several men described their work as a coping mechanism that helped normalise their lives and minimise the threat of PCa.

I was going to work [during treatment]. I finished my external beam radiotherapy nine to nine-fifteen [in the morning] and at ten o'clock, I am [working]. That was the way I could cope. You know, that was the way I could get over it and really cope. (Participant 14, BA)

A few men also described voluntary work and the pursuit of hobbies, such as gardening, exercise, and reading as additional sources of distraction:

I did a lot of reading, to get myself engaged and focussed and not worry about [PCa]. This helps to block out this issue and not worry about it. (Participant 2, BA)

\section{Non-disclosure of diagnosis}

Almost two thirds of $\mathrm{BA}$ and $\mathrm{BC}$ participants described a general reluctance to discuss health issues with friends and relatives, or to disclose their diagnosis beyond partners or immediate family:

It's only my immediate family, my wife and my children that I told. I didn't even tell my younger brother who's a GP. The rest of my other siblings, and family, I didn't tell them. ... I believe it's personal. (Participant $9, \mathrm{BA})$

Participants sometimes linked their preference to not share their diagnosis with others to selfreliance: Men of African origin are less likely to tell other people about it; they have a propensity not to see the doctor, they think they can cope (Participant 9, BA). Participants reported this tendency could be prevalent even amongst the highly educated:

People from my culture, they're very reticent about discussing medical issues in any great detail. I find even amongst my own relatives, some of whom are very, very well educated, they're not very forthcoming when it comes to discussing health issues. (Participant 10, BA)

However, non-disclosure may also be motivated by fear of hospitals, which one man reported were associated with death by West Indian men (Participant 1, BC). Another participant, born in the UK, described this attitude of non-disclosure as a generational thing, and stronger amongst older black men; formed at a time when visiting a doctor cost a lot of money, and perhaps relatedly, because men tended to use local remedies or traditional medicines (Participant 2, BA). No study participant reported using traditional remedies for their PCa: I was treated with herbal medicine in Africa, but I never had any in Europe (Participant 2, BA). Another British-born participant suggested the attitude of non-disclosure was stronger amongst men born in African and Caribbean countries than amongst black men born in the UK:

I just think that mentality [of non-disclosure] is probably less so with British born kids but I think that mentality is still there that you only go to the doctors if it's absolutely necessary rather than go to the doctors to make sure you are well. (Participant 7, BC)

Some participants indicated that non-disclosure of their diagnosis to others was related to the social stigma they might encounter:

The shame sometimes of the stigma is also very often the case that people don't want to talk about it because of the stigma that might be actually with such things. (Participant 5, BA).

Stigma was associated with conceptions of masculinity and sexual dysfunction, and one participant described how during a visit to Africa; his country of birth, friends advised him to go for treatment, 
but keep it quiet, because obviously people might think you have sexual problems (Participant 13, BA). Sexual dysfunction was described as:

...not something in our culture that we normally dwell on very much. To us as a man, it's dehumanising isn't it. It's not something that you can really talk about very much.

(Participant 13, BA)

\section{Active awareness-raising}

Despite the reticence of most participants to disclose their diagnosis, over a third of the sample responded to their diagnosis by becoming engaged in raising awareness of PCa amongst men in their community, often using social media: I use my social media page to put the word out (Participant 11, $\mathrm{BA})$. These men indicated they were unconcerned about publicly discussing their diagnosis: So I've got no qualms about speaking about it (Participant $6, \mathrm{BC}$ ). Participants were often motivated by surprise and concern when they became aware of the high prevalence of PCa amongst black men:

When I went to the clinic for the first diagnosis and the surgeon explained to me Asian, West Indian have a higher propensity to prostate cancer than other people, which was quite a shock because I didn't know that and that's why I tried to get the word out to as many people as I can. (Participant 6, BC)

When raising awareness and suggesting to other black men they should consider PSA testing, participants described the need to 'pitch' the conversation carefully, so as not to appear to be wishing evil upon them. This concern may also be related to the attitude of many men to maintain a positive front noted above:

As a black person, OK, I have three brothers, oh, I need to tell them. You've got to be careful. How you say that to them. Because the way we're risen is different with respect to negative things. So it will be that they say: oh, so are you wishing me evil. OK? ... Rather than: oh, that's true, maybe I should read about this and try to understand. It is most likely to be interpreted that you're wishing them evil.... So with black communities one has got to understand the audience very well in order to pitch that presentation. (Participant 2, BA)

\section{Seeking support from close community}

Most participants reported positive experiences of health services: Fantastic. The support and information I got from the NHS was really, really good (Participant 11, BA), though they rarely sought support from large charities such as Prostate Cancer UK or Macmillan following diagnosis.

Sometimes men described themselves as too shy (Participant 3, BA), perhaps connected to a reluctance to discuss their diagnosis, but more often they reported not needing such support. Only one participant briefly accessed a support group sign-posted by health professionals, and most described receiving emotional and social support solely from their families: [Wife]'s provided emotional support. She's provided all the support that is needed (Participant 5, BA), or from community groups linked to either their church or country of birth:

We have a [West African Country] Community Association and we meet up regularly ... and discuss issues, for example issues on prostate cancer, diabetes, on health issues in general. ... we have three or four who have had [PCa] and who have gone successfully for the treatment. We meet up and have a chat and a discussion about it.' (Participant 2, BA)

\section{DISCUSSION}


This paper adds to previous research on black men's experiences following a PCa diagnosis (Rivas et al. 2016; Bamidele et al. 2018a), and included the largest sample of BA men of any similar UK study. Similar to many recent studies (Anderson et al. 2013; Bache et al. 2012; Bamidele et al. 2018a; Brown et al. 2014; Nanton \& Dale 2011; Pedersen et al. 2012), we have combined BA and BC men. However, it should be recognised that there may be substantial heterogeneity within this grouping in relation to national origins, religion and language (Aspinall \& Chinouya 2008).

Nevertheless, several themes were identified as particularly pertinent to black British men. BA and $B C$ men were strongly influenced by faith beliefs; social pressures and upbringing led many to adopt an outwardly 'positive' attitude despite genuine concerns, and support was mostly sought through a strong engagement with the local community and immediate families. While strong reluctance to disclose their diagnosis existed amongst most $\mathrm{BA}$ and $\mathrm{BC}$ participants, others sought to raise awareness of $\mathrm{PCa}$, often in response to becoming aware of the higher prevalence of PCa amongst black men. Work and other activities were distractions to maintain normality, and the influence of perceptions of self-identity and stigma were strong. These themes strongly correlate with those identified in two recent qualitative syntheses (Rivas et al. 2016; Bamidele et al. 2018a). However, while poor relationships between $\mathrm{BA}$ and $\mathrm{BC}$ men and health care provider were a strong theme reported in previous literature (Rivas et al. 2016; Bamidele et al. 2018a), our UK-based study participants reported mainly positive experiences. These contrasting findings may be related to our method of participant recruitment or that the metasyntheses was dominated by US studies. Nevertheless, policy efforts within UK healthcare services have sought to develop greater cultural sensitivity to the needs of ethnic minorities (NICE 2018). Another contrast with previous research is that while black men in the UK have previously reported strong beliefs in traditional remedies to complement medical treatment for PCa (Nanton \& Vale 2011), none of our study participants reported using them.

Spirituality has previously been identified as a key coping strategy that empowers black men (Rivas et al. 2016; Bamidele et al. 2018a), providing spiritual strength to manage treatment side effects (Bache et al. 2012). African American men with PCa have been found to be unique in their descriptions of a 'personal' relationship with God (Jones et al. 2011). While some black men prefer to leave a cure to God (Hamilton et al. 2007; Maliski et al. 2010; Rivers et al. 2011), others describe a 'triumvirate' of God, clinician and patient, all playing their individual role (Jones et al. 2011; Hamilton et al. 2007), which accords with our findings. Similarly, the identified tendency to display a positive outlook to others corroborates previous studies that found black men striving to maintain a positive 'front' (Maliski et al. 2008; Fergus et al. 2002). The importance given to maintaining masculine physicality and working lives may also be a manifestation of men seeking to display a positive outward appearance. The combination of strong faith beliefs and being able to continue working may be particularly effective in helping these men cope after PCa diagnosis. Most participants were born outside the UK, and it has previously been argued that a strong motivational work ethic exists amongst people originating from Africa or Caribbean (Nanton \& Vale 2011; Brown 2014). However, work and other activities also served as distraction from PCa.

Most participants reported restricting knowledge of their diagnosis to very few family or friends, often not informing close relatives, similar to previous findings (Rivers et al. 2011; Zhang et al. 2015). A reluctance to disclose may have influenced some participants to not seek support from health professionals for issues such as ED, or to engage with PCa support groups when sign-posted to them. Previous evidence also indicated $B A$ and $B C$ men seek limited support from health professionals and gain most support from wives, families and church (Bamidele et al. 2018a). Some participants indicated non-disclosure strategies may be associated with self-reliance, and related to the reported 
tendency to 'deny the negative'. Amongst participants, non-disclosure was also sometimes related to fear of stigma and the association of PCa with ED and ideas of masculinity. Previous research identified an apparent magnified significance attached to ED amongst BA and BC men compared with Caucasian men (Mailiski et al. 2008; Bisson et al. 2002; Cliff \& Macdonagh et al. 2000; Gannon et al. 2010), and African Americans reportedly root manhood 'irrevocably' in sexual prowess (Rivers et al. 2011; Maliski et al. 2008; Fergus et al. 2002). However, a third of our participants were not only willing to disclose their diagnosis, but were keen to raise awareness of PCa and its prevalence amongst their peers, and encourage other black men to request a Prostate-Specific Antigen (PSA) screen. This high proportion of awareness-raisers may be a feature of our self-selecting sample. Recruitment was lower amongst this group than for the wider interview study; BA and BC men have been defined as 'hard to reach' groups and recruitment difficulties have arguably contributed to their under-representation in research associated with PCa (Bamidele et al. 2018b). When actively encouraging other black men to check their PSA status, a few participants described a need to be cautious in the way that message was 'pitched', to avoid appearing to 'wish evil' on others. This communication concern may also be linked to the theme of presenting an outward appearance of positivity amongst participants. Informing other men of potential dangers means asking them to acknowledge a possible negative, which they may not wish to do and may cause offence.

Men's awareness-raising activity was often conducted through religious communities, but sometimes also within work environments. Men also conducted awareness-raising using social media, not previously reported in previous reviews. Previous studies found BA and BC men viewed supporting other men (i.e. buddy activities) enhanced their own coping (Anderson et al. 2013; Gray et al. 2005) and social status (Gray et al. 2005). Although men can be initially reluctant to disclose their diagnosis to others, due to concerns about stigma and damaged masculinity, research indicates some men 're-frame' their concept of manhood, shifting priorities from sexuality to sustaining self and social identities by warning others of the disease (Rivas et al. 2016; Maliski et al. 2010). The shift might also be associated with faith beliefs, and the Biblical teaching to 'do unto others' (Hamilton \& Sandelowski 2003). It may also be related to perceptions of positivity and resilience, while other men sometimes reportedly bargained with God, promising to educate others about PCa in return for survival (Maliski et al. 2010). Drawing on local 'champions' (i.e. black men living with PCa) to raise awareness and provide peer support has previously been recommended to facilitate black men's access to PCa information and health services, conducted in venues accessible and acceptable to black communities (Pedersen et al. 2012). This study suggests local champions may also 'pitch' information in a culturally sensitive way.

\section{STUDY LIMITATIONS}

Participant response rates were lower amongst $B A$ and $B C$ men than amongst the wider sample, both to the LAPCD survey and subsequent invitations to be interviewed. The small number of participants did not allow comparison of coping strategies adopted by $\mathrm{BA}$ and $\mathrm{BC}$ men, or between men born and raised in the UK and those not. Furthermore, all participants were heterosexual. The sample comprised men who had both completed the survey and indicated willingness to be interviewed, and then consented to an interview once approached. These men may differ from men who either did not complete the survey or did not agree to be contacted for an interview. Nevertheless, members of the UAG, including a BA man, read through transcripts and confirmed identified themes. Themes broadly reflected those identified within qualitative reviews (Rivas et al. 2016; Bamidele et al. 2018a).

\section{CONCLUSION}


Themes identified within the data broadly converged with previous studies, despite most having been conducted in US. Differences included overwhelmingly positive experiences reported of the health service and professionals, use of social media by black men to raise awareness of PCa amongst peers, and the need to carefully pitch information. Implications of this study include clinicians continuing to improve cultural sensitivity when providing patient-centred care. Adaptive strategies may be promoted amongst $\mathrm{BA}$ and $\mathrm{BC}$ men by challenging stigma of $\mathrm{PCa}$, encouraging disclosure, reframing masculinity, awareness-raising and providing information. More research is needed to determine how best to convey awareness-raising messages to black men. 


\section{References}

Anderson B., Marshall-Lucette S., Webb P. (2013). African and Afro-Caribbean men's experiences of prostate cancer. British Journal of Nursing 22: 1296-1307.

Aspinall P., Chinouya M. (2008). Is the standardised term 'Black African' useful in demographic and health research in the United Kingdom. Ethnicity and Health 13(3): 183-202.

Bache R.A., Bhui K.S., Dein S., Korszun A. (2012). African and Black Caribbean origin cancer survivors: A qualitative study of the narratives of causes, coping and care experiences. Ethnicity \& Health, 17 187-201.

Bamidele O.O., McGarvey H.E., Lagan B.M., Chinegwundoh F., Ali N., McCaughan E. (2018a). "Hard to reach, but not out of reach": Barriers and facilitators to recruiting Black African and Black Caribbean men with prostate cancer and their partners into qualitative research. European Journal Cancer Care e12977. https://doi.org/10.1111/ecc.12977.

Bamidele O., McGarvey H., Lagan B.M., Ali N., Chinegwundoh F., Parahoo K., McCaughan E. (2018b). Life after prostate cancer: A systematic literature review and thematic synthesis of the post- treatment experiences of Black African and Black Caribbean men. European Journal Cancer Care 27:e12784; 1-14.

Ben-Shlomo Y., Evans S., Ibrahim F., Patel B., Anson K., Chinegwundoh F., Corbishley C., Dorling D. et al. (2008). Prostate cancer: The risk of prostate cancer amongst black men in the United Kingdom: The PROCESS Cohort Study. European Urology 53: 99-105.

Bisson J.I., Chubb H.L., Bennett S., Mason M., Jones D., Kynaston H. (2002). The prevalence and predictors of psychological distress in patients with early localized prostate cancer. British Journal of Urology International 90(1):56-61.

Bray F., Ferlay J., Soerjomataram I., Siegal R.L., Torre L.A., Jemal A. (2018). Global Cancer Statistics 2018: GLOBOCAN Estimates of Incidence and Mortality Worldwide for 36 Cancers in 185 Countries. CA Cancer Journal for Clinicians 68:394-424

Brown M. (2014). African and African-Caribbean Londoners' experiences of cancer services: A narrative approach. Doctoral thesis, University of West London.

Cancer Research UK. (2018). Prostate Cancer Statistics

https://www.cancerresearchuk.org/health-professional/cancer-statistics/statistics-by-cancertype/prostate-cancer

Chinegwundoh F. (2006). Risk and presenting features of prostate cancer amongst AfricanCaribbean, South Asian and European men in North-east London. British Journal of Urolology International 98(6): 1216-20. doi: 10.1111/j.1464-410X.2006.06503.x.

Cliff A.M., Macdonagh R.P. (2000). Psychosocial morbidity in prostate cancer: II. A comparison of patients and partners. British Journal of Urological International 86(7):834-839.

Downing A., Wright P., Wagland R., Watson E., Kearney T., Mottram R., Allen M., Cairnduff V. et al (2016). Life After Prostate Cancer Diagnosis: Protocol for a UK-wide patient-reported outcomes study. BMJ Open 2016;6:e013555.doi:10.1136/bmjopen-2016-013555.

Fergus K.D., Gray R.E., Fitch M.I. (2002). Sexual dysfunction and the preservation of manhood: experiences of men with prostate cancer. Journal of Health Psychology 7(3):303-316. 
Gannon K., Guerro Blanco M., Patel A., Abel P. (2010). Reconstructing masculinity following radical prostatectomy for prostate cancer. Aging Male 13(4):258-264.

Gale N.K., Heath G., Cameron E., Rashid S., Redwood S. (2013). Using the framework method for the analysis of qualitative data in multi-disciplinary health research. BMC Medical Research Methodology 13: 117.

Gavin A.T., Drummond F.J., Donnelly C., O'Leary E., Sharp L., Kinnear H.R. (2015). Patientreported 'ever had' and 'current' long- term physical symptoms after prostate cancer treatments. BJU International, 116, 397-406.

Gray R.E., Fergus K.D., Fitch M.I. (2005). Two Black men with prostate cancer: A narrative approach. British Journal of Health Psychology 10: 71-84.

Haiman C.A., Chen G.K., Blot W.J., Strom S.S., Berndt S.I., Kittles R.A., Rybicki B.A., Isaacs W.B. et al. (2011). Characterizing Genetic Risk at Known Prostate Cancer Susceptibility Loci in African Americans. PLoS Genetics 2011;7:e1001387.

Hamilton J.B., Sandelowski M. (2003). Living the golden rule: reciprocal exchanges among African Americans with cancer. Qualitative Health Research 13(5): 656-674.

Hamilton J.B., Powe B.D., Pollard A.B. III, Lee K.J., Felton A.M. (2007). Spirituality among African American cancer survivors: having a personal relationship with God. Cancer Nursing 30(4):309316.

Han Y., Signorello L.B., Strom S.S., Kittles R.A., Rybicki B.A., Stanford J.L., Goodman P.J., Berndt S.I., et al. (2015) Generalizability of established prostate cancer risk variants in men of African ancestry. International Journal of Cancer 136: 1210-1217.

Jones A.L., Chinegwundoh F. (2014). Update on prostate cancer in black men within the UK ecancermedicalscience 8, 455 .

Jones R.A., Wenzel J., Hinton I., et al. (2011) Exploring cancer support needs for older African American men with prostate cancer. Supportive Care in Cancer 19(9):1411-1419.

Lloyd T., Hounsome L., Mehay A., Mee S., Verne J., Cooper A. (2015). Lifetime risk of being diagnosed with, or dying from, prostate cancer by major ethnic group in England 2008-2010. BMC Medicine. 2015; 13: 171. doi: 10.1186/s12916-015-0405-5.

Maliski S.L., Connor S.E., Williams L., Litwin M.S. (2010). Faith among low income, African American/black men treated for prostate cancer. Cancer Nursing 33(6):470-478.

Maliski S.L., Rivera S., Connor S., Lopez G., Litwin M.S. (2008). Renegotiating masculine identity after prostate cancer treatment. Qualitative Health Research 18(12):1609-1620.

Metcalfe C., Evans S., Ibrahim F. et al. (2008). Pathways to diagnosis for Black men and White men found to have prostate cancer: the PROCESS cohort study. British Journal of Cancer 99(7) 1040-1045.

Nanton V., Dale J. (2011). 'It don't make sense to worry too much': The experience of prostate cancer in African- Caribbean men in the UK. European Journal of Cancer Care 20: 62-71. 
National Institute for Health and Care Excellence (2018). Promoting health and preventing premature mortality in black, Asian and other minority ethnic groups: Quality standard.

Published: 11 May 2018. nice.org.uk/guidance/qs167.

Paterson C., Robertson A., Smith A., Nabi G. (2015). Identifying the unmet supportive care needs of men living with and beyond prostate cancer: A systematic review. European Journal of Cancer Care 19(4): 405-418.

Pedersen V.H., Armes J., Ream E. (2012). Perceptions of prostate cancer in Black African and Black Caribbean men: a systematic review of the literature. Psycho-Oncology 21: 457- 468.

Rebbeck T.R., Devesa S.S., Chang B.L., Bunker C.H., Cheng I., Cooney K., Eeles R., Fernandez P. (2013). Global patterns of prostate cancer incidence, aggressiveness, and mortality in men of African descent. Prostate Cancer, 2013, 560857.

Rivas C., Mattheson L., Naoyan J., Glaser A., Gavin A., Wright P., Wagland R., Watson E. (2016). Ethnicity and the prostate cancer experience: a qualitative metasynthesis. Psycho-Oncology 25: 1147-1156. doi: 10.1002/pon.4222

QSR International Pty Ltd, 2012.

Ritchie J., Lewis J. (2011). Qualitative research practice: a guide for social science students and researchers. Sage, London, 2003.

Rivers B.M., August E.M., Gwede C.K., et al. (2011). Psychosocial issues related to sexual functioning among African- American prostate cancer survivors and their spouses. PsychoOncology, 20, 106-110. https://doi.org/10.1002/pon.1711|

Spendlow J.S., Joubert H.E., Lee H., Fairhurst B.R. (2018). Coping and adjustment in men with prostate cancer: a systematic review of qualitative studies. Journal of Cancer Survivorship 12: 155-168. doi.org/10.1007/s11764-017-0654-8

Zhang A.Y., Gary F., Zhu H. (2015). Attitudes toward cancer and implications for mental health outcome in African-American cancer patients. Journal of Cancer Education 30(1):138-144. doi.org/10.1007/s13187-014-0704-0 
Table 1: Study sample groups: Overall LAPCD sample and BA/BC sample

\begin{tabular}{|c|c|c|c|}
\hline \multirow{2}{*}{\multicolumn{2}{|c|}{ Characteristic }} & \multicolumn{2}{|c|}{ Interview samples } \\
\hline & & \multirow{2}{*}{$\begin{array}{c}\begin{array}{c}\text { Overall LAPCD } \\
\text { sample } \\
\mathrm{n}=146(100 \%)\end{array} \\
66.7\end{array}$} & \multirow{2}{*}{$\begin{array}{c}\text { BA and BC sample } \\
\mathrm{N}=14(\mathbf{1 0 0 \% )})\end{array}$} \\
\hline Age & Mean & & \\
\hline & Median & TBA & 66 \\
\hline & Range & $48-94$ & $55-85$ \\
\hline \multirow[t]{4}{*}{ Nation } & England & $96(65.7)$ & $11(78.6)$ \\
\hline & Wales & $15(10.2)$ & $2(14.3)$ \\
\hline & Scotland & $18(12.3)$ & $0(0.0)$ \\
\hline & Northern Ireland & $17(11.6)$ & $1(7.1)$ \\
\hline \multirow[t]{5}{*}{ Disease stage } & 1 & $45(30.8)$ & $4(28.6)$ \\
\hline & $\mathrm{II}$ & $30(20.5)$ & $4(28.6)$ \\
\hline & III & $25(17.2)$ & $3(21.4)$ \\
\hline & IV & $25(17.2)$ & $2(14.3)$ \\
\hline & Missing & $31(21.2)$ & $1(7.1)$ \\
\hline \multirow[t]{2}{*}{ Marital Status } & Partnered & $110(75.3)$ & $9(64.3)$ \\
\hline & Single & $36(24.7)$ & $5(35.7)$ \\
\hline \multirow[t]{2}{*}{ Sexual Orientation } & Heterosexual & $127(89.0)$ & $14(100)$ \\
\hline & Homosexual & $19(13.0)$ & $0(0.0)$ \\
\hline \multirow[t]{3}{*}{ Ethnicity } & White & $129(88.4)$ & $0(0.0)$ \\
\hline & Black African, Black Caribbean & $14(9.6)$ & $14(100)$ \\
\hline & Asian & $3(2.0)$ & $0(0.0)$ \\
\hline \multirow[t]{12}{*}{ Treatment } & Radical Prostatectomy +/- Other & $23(15.7)$ & $6(42.9)$ \\
\hline & Radical Radiotherapy only & $6(4.1)$ & $0(0.0)$ \\
\hline & Radical Brachytherapy only & $4(2.7)$ & $0(0.0)$ \\
\hline & Radiotherapy + ADT & $32(21.2)$ & $4(28.6)$ \\
\hline & Brachytherapy + ADT & $5(3.4)$ & $0(0.0)$ \\
\hline & Surgery + ADT & $13(8.9)$ & $0(0.0)$ \\
\hline & ADT only & $13(8.9)$ & $1(7.1)$ \\
\hline & Abiraterone/ Enzalutamide & $9(6.2)$ & $0(0.0)$ \\
\hline & Active surveillance & $21(14.4)$ & $1(7.1)$ \\
\hline & Watchful waiting & $11(7.5)$ & $1(7.1)$ \\
\hline & HIFU & $4(2.7)$ & $0(0.0)$ \\
\hline & Chemotherapy +/- Other & $5(3.4)$ & $1(7.1)$ \\
\hline
\end{tabular}


Table 2: BA/BC men: Individual participant socio-demographic and treatment characteristics

\begin{tabular}{|c|c|c|c|c|c|c|c|}
\hline Participant & Age & Marital status & Ethnicity & Employment & Stage & Place of Birth & Treatment \\
\hline 01 & 66 & Divorced/ single & Black Caribbean & Employed & 1 & Caribbean & $\mathrm{RP}$ \\
\hline 02 & 70 & Married & Black African & Employed & 3 & Africa & EBRT, ADT \\
\hline 03 & 59 & Married & Black African & Employed & 1 & Africa & AS \\
\hline 04 & 58 & Married & Black African & Employed & 2 & Africa & $\mathrm{RP}$ \\
\hline 05 & 59 & Married & Black African & Employed & 2 & Africa & $\mathrm{RP}$ \\
\hline 06 & 55 & Married & Black Caribbean & Employed & 1 & UK & $\mathrm{RP}$ \\
\hline 07 & 77 & Single & Black Caribbean & Retired & 4 & Caribbean & EBRT, Chemo \\
\hline 08 & 72 & Divorced/ single & Black Caribbean & Retired & 2 & Caribbean & $\mathrm{RP}$ \\
\hline 09 & 74 & Single & Black African & Employed & 4 & Africa & ADT \\
\hline 10 & 85 & Married & Black African & Retired & 1 & Africa & WW \\
\hline 11 & 57 & Single & Black African & Employed & 3 & Africa & EBRT, BT, ADT \\
\hline 12 & 60 & Married & Black African & Employed & 3 & UK & RP, EBRT \\
\hline 13 & 69 & Married & Black African & Retired & 2 & Africa & EBRT, ADT \\
\hline 14 & 58 & Married & Black African & Employed & 3 & Africa & EBRT, ADT, BT \\
\hline
\end{tabular}

